Conclusions Although some safer-sex services were available at Burning Man in 2010, attendees reported unprotected intercourse with new partners during the event, a behaviour that confers high risk for STI acquisition. Large gatherings such as Burning Man might present opportunities for rapid STI transmission among geographically diverse sexual networks. Local health jurisdictions, both in the host location and those in which event attendees reside, should consider further assessment of STI transmission and prevention at Burning Man and similar events.

\section{P2-S3.02 LATENT CLASS ANALYSIS OF SEXUAL RISK PATTERNS AMONG HETEROSEXUALLY-IDENTIFIED, SOCIALLY MARGINALISED MEN IN URBAN, COASTAL PERU}

doi:10.1136/sextrans-2011-050108.321

${ }^{1} \mathrm{~K}$ Konda, ${ }^{2} \mathrm{D}$ Celentano, ${ }^{3} \mathrm{~S}$ Kegeles, ${ }^{1} \mathrm{~T}$ Coates, ${ }^{4} \mathrm{C}$ Caceres, ${ }^{5} \mathrm{NIMHCollaborative} \mathrm{HIV/}$ STD Prevention Trial Group. ${ }^{1}$ UCLA, Lima, Peru; ${ }^{2} J o h n s$ Hopkins University, USA; ${ }^{3}$ UCSF, USA; ${ }^{4}$ UPCH, Peru; ${ }^{5}$ NIMH, USA

Introduction We explored patterns of sexual risk behaviour in a population of heterosexually-identified Peruvian men using latent class analysis, a technique that creates classes based on response patterns to questions related to a latent variable. In this study, the latent variable of interest is sexual risk behaviour.

Methods We used data from the Peru site of the National Institute of Mental Health (NIMH) Collaborative HIV/STD Prevention Trial to investigate patterns of high-risk behaviour among heterosexuallyidentified men $(n=2109)$. Seven sexual risk behaviours were analysed in latent class analysis to group men into risk classes. These selfreported behaviours included using drugs in the past month, using alcohol or drugs prior to sex, having 3 or more sex partners in the past 6 months, having concurrent sex partnerships, exchanging sex for money, and having a male sex partner in the past 6 months.

Results Four latent classes of risk were identified, of which two classes had lower probabilities of these risk behaviours and two classes had higher risk classes probabilities of these risk behaviours. Increasing probability of risk behaviours by classes was significantly correlated with increasing reports of unprotected sex ( $p$ value for trend test $<0.001)$. HIV/STI prevalence was elevated in all classes and prevalence increased with increasing probability of reporting the risk behaviours, although the differences were not significant. The risk behaviours in two of the latent classes identified were primarily related to alcohol and drug use.

Conclusions Risk behaviours in this population of heterosexuallyidentified men vary by latent class; however, given HIV/STI prevalence in each class all require prevention interventions. Interventions should also focus on alcohol and drug use, as these are important risk factors for this population. Future behavioural interventions for the prevention of HIV/STI infection may benefit from this information by tailoring messages to fit the observed patterns risk.

\section{P2-S3.03 EXPLORING PERCEPTIONS OF THE SOCIAL DETERMINANTS OF STIS IN AFRICAN AMERICAN COMMUNITIES OF THE USA}

doi:10.1136/sextrans-2011-050108.322

${ }^{1} \mathrm{~A}$ Friedman, ${ }^{1} \mathrm{~A}$ Forsythe, ${ }^{2} \mathrm{~J}$ Poehlman, ${ }^{2} \mathrm{~S}$ Harris, ${ }^{3} \mathrm{~J}$ Smith, ${ }^{2} \mathrm{~J}$ Uhrig. ${ }^{1} \mathrm{CDC}$, Atlanta, USA; ${ }^{2}$ RTI International, USA; ${ }^{3}$ University of North Carolina, Chapel Hill, USA

Background African Americans (AAs) make up 12\% of the US population, yet they account for about half of all reported chlamydia and syphilis cases, and 70\% of gonorrhoea cases. Targeted, culturally sensitive interventions are needed to address these disparities. This study sought to explore how AAs perceive STIs in their communities, and what they feel should be done to address the problem.

Methods Triads $(n=31)$ and individual interviews $(n=64)$ were conducted with sexually active, heterosexual AA adults, ages 18-45, in four communities with high STI incidence. Triads were segmented by age, gender, and urban/rural residence. Interviewers (gender/race-matched) used a semi-structured guide to explore awareness and importance of the STI problem in AA communities, perceptions of contributing factors and high-risk groups, and suggested solutions. Discussions were audio-taped and transcribed. A team of three analysts coded transcripts using OSR NVivo8, based on a codebook developed from identified themes.

Results A total of 158 adults participated. Overall, STDs were believed or presumed to be very common in AA communities. Many had heard about the disparate STD/HIV rates on the news/TV or in school. Men were more likely to challenge this, reasoning that AAs are heterogeneous and that STIs are more likely influenced by socioeconomic status (SES) than race. Participants identified youth, low SES groups, drug addicts, Sex workers, homosexuals, and men on the down low as highest-risk groups. Promiscuity and a lack of sexual-health education, care for self/others/future, and health-care access were seen as major causes. Other contributing factors were teen pregnancy/family disintegration, gangs, drugs, school dropouts, unemployment, poverty, boredom, hopelessness, male/female ratio, partner concurrency, and the media. Overall, STIs were seen as a relatively low priority. Yet most felt that change is critical and could be promoted through music, mass media, faithbased/community/organizational, electronic and interpersonal channels. Increasing information, education, and healthcare access; and developing parenting, self-esteem boosting, and mentoring programs were suggested.

Conclusions STDs among AAs are recognised as a likely consequence of many underlying social, structural and community ills, which must be addressed to reduce STD disparities. Traditional STD prevention efforts must be supported by non-traditional social/ structural interventions.

\section{P2-S3.04 CONDOM USE AMONG US ADULTS AT LAST SEXUAL INTERCOURSE, 1996-2008: AN ANALYSIS OF GENERAL SOCIAL SURVEY (GSS) DATA}

doi:10.1136/sextrans-2011-050108.323

${ }^{1} \mathrm{~L}$ Warner, ${ }^{1} \mathrm{~J}$ Anderson, ${ }^{2} \mathrm{M}$ Macaluso. ${ }^{1} \mathrm{CDC}$ Atlanta, USA; ${ }^{2}$ Cincinatti Children's Center, Cincinatti, USA

Background Public health programs have sought to increase the use of condoms among persons at risk for transmitting or acquiring sexually transmitted infection. Although data from national health surveys have indicated increasing trends in condom use among adults since the onset of the HIV epidemic, little is known about recent national trends in usage.

Methods Questions on condom use at last sexual intercourse were added to the General Social Survey, a nationally representative survey of US adults 18 and older conducted in alternating years, beginning in 1996. Using data from 1996 to 2008, the prevalence of condom use at last intercourse was estimated, and trends and correlates of this measure were evaluated.

Results Across the 13-year period, condom use was reported by $20.2 \%$ of respondents during their most recent intercourse. Use was significantly higher for sex outside ongoing relationships as compared to within relationships, ( $46.4 \%$ vs $18.1 \%$, respectively) and among those with 2 or more past-year sex partners as compared to one partners $(44.7 \%$ vs $15.6 \%)$. A statistically significant increasing 1996-2008 trend in condom use was detected overall, but not for use within partnership type or by number of partners. 